\title{
Correction to: Control of Intestinal Epithelial Proliferation and Differentiation: The Microbiome, Enteroendocrine L Cells, Telocytes, Enteric Nerves, and GLP, Too
}

\author{
Jonathan D. Kaunitz ${ }^{1,3,4}$ (D) Yasutada Akiba ${ }^{2,3}$
}

Published online: 10 December 2019

(c) Springer Science+Business Media, LLC, part of Springer Nature 2019

\section{Correction to: \\ Digestive Diseases and Sciences (2019) 64:2709-2716 \\ https://doi.org/10.1007/s10620-019-05778-1}

The original version of the article unfortunately contained an error in one of the sentences. The sentence, "Eventually, Dan Drucker in Pat Brubaker's laboratory convincingly demonstrated that GLP-2 is the proglucagon product controlling intestinal proliferation [19]," should read "Eventually, Dan Drucker convincingly demonstrated that GLP-2 is the proglucagon product controlling intestinal proliferation [19]."

Publisher's Note Springer Nature remains neutral with regard to jurisdictional claims in published maps and institutional affiliations.

The original article can be found online at https://doi.org/10.1007/ s10620-019-05778-1.

Jonathan D. Kaunitz jake@ucla.edu

1 Medical Service, West Los Angeles VAMC, Los Angeles, CA, USA

2 Research Service, West Los Angeles VAMC, Los Angeles, CA, USA

3 Department of Medicine, David Geffen School of Medicine at UCLA, Los Angeles, CA, USA

4 Department of Surgery, David Geffen School of Medicine at UCLA, Los Angeles, CA, USA 